\title{
VIGOR DE SEMENTES ARMAZENADAS DE IPÊ-AMARELO Tabebuia serratifolia (VAHL.) NICH ${ }^{1}$
}

\begin{abstract}
Vênia Camelo de Souza ${ }^{2}$, Riselane de Lucena Alcântara Bruno ${ }^{3}$ e Leonaldo Alves de Andrade ${ }^{3}$
RESUMO - O objetivo deste trabalho foi determinar as melhores condições e períodos de armazenamento adequados a tipos de conservação do vigor das sementes de ipê-amarelo. O experimento foi instalado no Laboratório de Análise de Sementes do CCA/UFPB, seguindo-se um delineamento inteiramente casualizado. Os tratamentos constituíram-se de sementes de ipê-amarelo acondicionadas em dois tipos de embalagens (papel e polietileno); três condições de armazenamento (câmara, laboratório e geladeira); e seis períodos de armazenamento ( 0 , 30, 60, 90, 120 e 150 dias). As características avaliadas foram: teor de água, Índice de Velocidade de Germinação (IVG) e comprimento e massa seca de plântulas. Os resultados de IVG, comprimento e massa seca de plântulas foram submetidos à análise de regressão polinomial. As sementes de ipê-amarelo acondicionadas na embalagem de papel apresentaram maior teor de água ao longo do armazenamento, nos ambientes de câmara e condições normais de laboratório. Em geral, as sementes acondicionadas nas embalagens de papel e polietileno e armazenadas no ambiente de laboratório perderam mais rapidamente o vigor ao longo do armazenamento.
\end{abstract}

Palavras-chave: Semente florestal, embalagem e ambientes.

\section{VIGOR OF STORED SEEDS OF YELLOW-IPE Tabebuia serratifolia (VAHL.) NICH}

\begin{abstract}
This work aimed to determine the best conditions and storage periods adapted to the types of conservation of seed vigor for yellow-ipe. The experiment was conducted at the Laboratory of Analysis of Seeds - CCA/UFPB, using an entirely randomized design. The treatments consisted of yellow-ipe seeds packaged in (paper and polyethylene bags, three storage conditions (chamber, room temperature and humidity conditions and refrigerator) and six storage periods (0,30,60, 90, 120 and 150 days). The evaluated characteristics were: moisture content, Germination Speed Index (GSI), seedling length, and seedling dry matter. The results of GSI, seedling length and seedling dry matter were subjected to the analysis of polynomial regression. The yellow-ipe seeds packaged in paper bags presented higher moisture content along the storage in the chamber and room temperature and humidity conditions. In general, the seeds kept in paper packaging and polyethylene bags and stored in room temperature and humidity conditions lost the vigor more quickly along the storage.
\end{abstract}

Keywords: Forest seed, packaging and storage conditions.

\section{INTRODUÇÃO}

O armazenamento de sementes de espécies florestais pode ser uma técnica relativamente econômica para assegurar valiosos germoplasmas (BONNER, 1990), considerando-se a não-ocorrência de frutificação de algumas espécies; além da intervenção do homem por meio de derrubadas e, ou, queimadas, eliminando áreas produtoras de sementes e espécies que frutificam de dois em dois anos (SOUZA et al., 1980).

Dentre as espécies florestais, destaca-se o ipêamarelo, cujas sementes apresentam curto período de vida, com anos de baixa ou nenhuma produção, o que

\footnotetext{
${ }^{1}$ Recebido em 16.06.2003 e aceito para publicação em 10.08.2005.

${ }^{2}$ Bolsista da CAPES-CCA/UFPB. 58397-000 Areia - PB.E-mail: <venia @ areianet.com.br>.

${ }^{3}$ Departamento de Fitotecnia do CCA/UFPB. Areia - PB.
} 
limita a dispersão natural, bem como sua utilização em viveiros para reflorestamento e comércio de mudas, tornando-se necessário conhecer suas condições ideais de armazenamento. Leão (1984) afirmou que a conservação de sementes de essências florestais é de fundamental importância quando se visa ao desenvolvimento de programas silviculturais.

Pela importância das diferentes espécies e da curta longevidade natural de suas sementes, pesquisas envolvendo o armazenamento das sementes de ipê vêm sendo desenvolvidas e publicadas desde a década de 1970 (SILVA et al., 2001). A curta longevidade natural das sementes de ipê está ligada à pequena quantidade de substâncias de reserva armazenadas na semente e ao elevado teor de óleo em sua composição química (DEGAN et al., 2001). Os resultados dessas pesquisas vêm comprovando o comportamento ortodoxo das sementes, caracterizado por Roberts (1973), pela eficiente conservação com baixo teor de água e armazenagem em ambiente com baixos níveis de temperatura e umidade relativa do ar.

Um dos aspectos mais pesquisados nos últimos anos tem sido a qualidade fisiológica das sementes, em decorrência de estarem sujeitas a uma série de mudanças degenerativas após a sua maturação. Nesse sentido, além das condições ambientais de armazenamento, o tipo de embalagem tem influência significativa na qualidade fisiológica das sementes (CARVALHO e NAKAGAWA, 2000).

Como os estudos tecnológicos das sementes são efetivamente o ponto de partida para utilização e exploração de forma racional das espécies nativas, este trabalho se propôs a avaliar condições adequadas à conservação das sementes de ipê-amarelo.

\section{MATERIAL E MÉTODOS}

As sementes de Tabebuia serratifolia (VAHL.) NICH foram coletadas em fevereiro de 2002, no município de Areia, PB, no solo, na área de projeção da copa da árvore e logo após a abertura natural do fruto.

O experimento foi conduzido no Laboratório de Análise de Sementes do Centro de Ciências Agrárias (LSCCA), da Universidade Federal da Paraíba (UFPB), de fevereiro a agosto de 2002, para avaliar a conservação da qualidade fisiológica das sementes, considerandose os efeitos de embalagem (saco de papel e saco de polietileno de 0,3 $\mathrm{mm}$ de espessura), ambiente (câmara, laboratório e geladeira) e períodos de armazenamento $(0,30,60,90,120$ e 150 dias $)$.

Antes da instalação do experimento, procedeuse à determinação do teor de água das sementes provenientes de cada coleta, efetuando-se posteriormente a homogeneização destas, tendo em vista que os resultados de umidade foram uniformes. Em sacos de papel e polietileno com capacidade para dois quilos, foram colocados em cada um desses $45 \mathrm{~g}$ de sementes, sendo essas embalagens, em seguida, etiquetadas, lacradas devidamente com fita adesiva e levadas aos três ambientes de armazenamento (câmara, laboratório e geladeira). Cada ambiente continha 12 embalagens (seis plásticas e seis de papel), referentes a cada período de armazenamento $(0,30,60,90,120$ e 150 dias $)$.

Durante o período experimental foram registrados os dados de temperatura e umidade relativa. Na câmara úmida, a temperatura e umidade relativa apresentaram valores de $22 \pm 3{ }^{\circ} \mathrm{C}$ e $74 \pm 2 \%$, respectivamente. No laboratório, os valores foram de $27 \pm 3{ }^{\circ} \mathrm{C}$ e $62 \pm 2 \%$, para temperatura e umidade relativa, respectivamente. Na geladeira, a temperatura foi de $7{ }^{\circ} \mathrm{C}$ e umidade relativa de $54 \%$ constantes.

Antes de cada período de armazenamento, as sementes procedentes de cada tratamento foram avaliadas, de acordo com as seguintes características:

Teor de água - Foi utilizado o método de estufa a $105 \pm 3^{\circ} \mathrm{C}$, durante 24 horas (BRASIL, 1992), utilizando-se $3 \mathrm{~g}$ de sementes por repetição, totalizando três repetições.

Índice de velocidade de germinação (IVG) - As sementes foram semeadas em substrato rolo de papel, umedecido com solução de nistatina $1 \%$, mantidas em germinador à temperatura constante de $25^{\circ} \mathrm{C}$, fotoperíodo de $8 / 24$ h e durante 21 dias, utilizando-se quatro repetições de 25 sementes em cada tratamento. A contagem das plântulas emergidas foi efetuada diariamente, utilizando-se como critério a emissão de raiz primária com comprimento $=\mathrm{a} 0,5 \mathrm{~cm}$ para $\mathrm{o}$ cálculo do índice de velocidade de germinação (IVG), conforme Maguire (1962), encerrando no momento em que esta se manteve constante.

Comprimento de plântulas - A avaliação foi efetuada aos 21 dias de germinação, obtendo-se a média do comprimento da parte aérea e da raiz de 10 plântulas normais, escolhidas ao acaso, por tratamento/repetição. 
Massa seca de plântulas - Após a medição do comprimento das plântulas, foram separadas raiz e parte aérea, colocadas em sacos de papel e levados à estufa com circulação de ar a $65^{\circ} \mathrm{C}$. A massa seca de raiz e da parte aérea foi determinada após $48 \mathrm{~h}$.

O delineamento empregado foi o inteiramente casualizado, em parcelas subdivididas, sendo os ambientes (câmara, laboratório e geladeira) as parcelas, as embalagens (saco de papel ou saco de polietileno) a subparcela e os períodos (total de seis) as subsubparcelas. Os dados das seguintes variáveis: índice de velocidade de germinação, comprimento de plântulas e massa seca de plântulas foram submetidos à análise de regressão polinomial, utilizando-se o programa SAEG (1993). Para escolha do modelo de regressão que melhor se ajustasse aos dados observados, levaram-se em consideração o fato de o desvio da regressão ser não-significativo e o modelo de maior ordem apresentar grau significativo e, por último, o valor do coeficiente de determinação $\left(\mathrm{R}^{2}\right)$; do contrário, optou-se por apresentar os resultados da tendência seguida pelos pontos observados.

\section{RESULTADOS E DISCUSSÃO}

De acordo com o teor de água das sementes de ipê-amarelo armazenadas (Figura 1), observa-se que elas foram armazenadas com $8 \%$ de umidade inicial, estando de acordo com Figliolia (1988), que classificou sementes do gênero Tabebuia como ortodoxas e deveriam ser armazenadas com teor de água em torno de $8 \%$.

No ambiente de câmara (Figura 1A), o comportamento das sementes foi diferente nas duas embalagens. No saco de papel, houve acréscimo no teor de água, atingindo porcentual de $11 \%$, decrescendo para $9 \%$ no final do armazenamento, o que também ocorreu na embalagem de polietileno. Com exceção de zero e 150 dias de armazenamento, as sementes acondicionadas em saco de polietileno apresentaram teor de água inferior ao das acondicionadas em saco de papel.

No ambiente de laboratório, na embalagem de papel a umidade das sementes aumentou por 30 dias e se manteve constante até aos 90, ocorrendo, posteriormente, aumento até os 120 dias, porém reduzindo para $10 \%$ no final do armazenamento. Já na embalagem de polietileno houve pequenas variações de umidade, com tendência de aumento ao longo do período experimental.

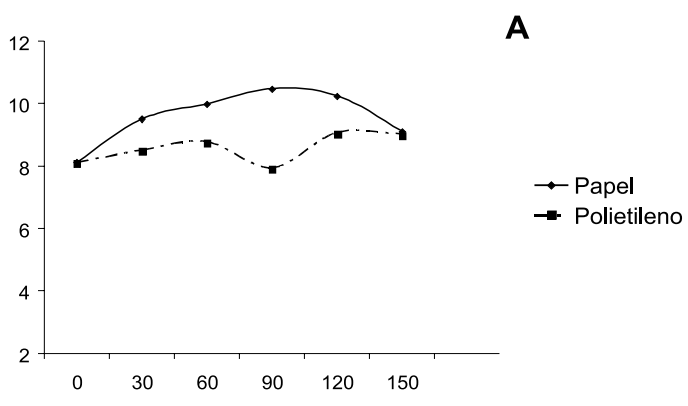

B
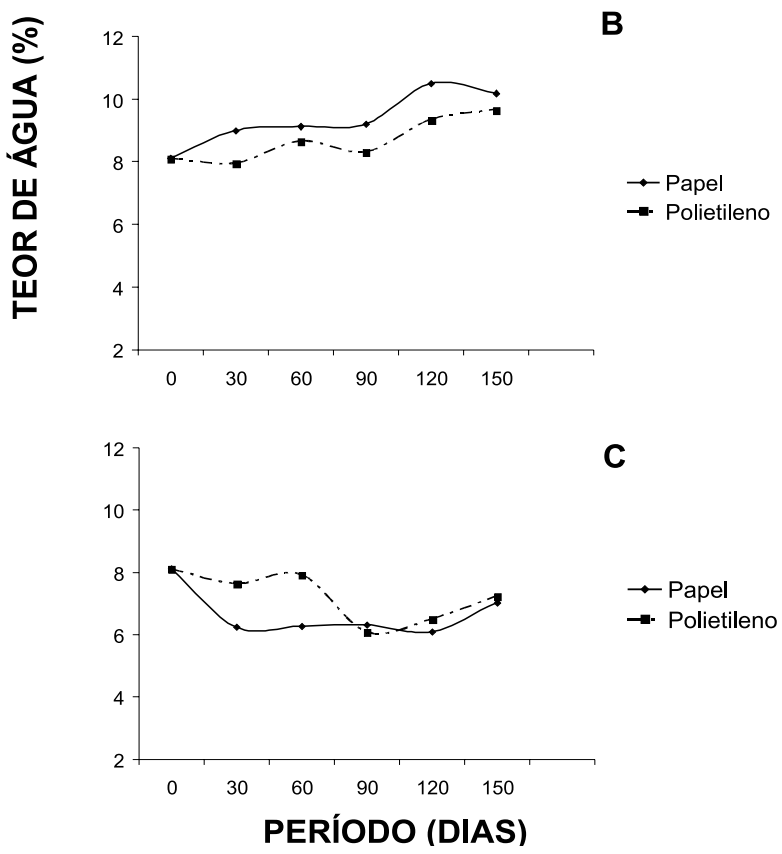

Figura 1 - Teor de água de sementes de ipê-amarelo acondicionadas em sacos de papel e polietileno, sob diferentes condições de armazenamento por 150 dias. $\mathrm{A}=$ câmara, $\mathrm{B}=$ laboratório e $\mathrm{C}=$ geladeira.

Figure 1 - Moisture content of seeds of yellow-ipe stored in paper and polyethylene bags, under different conditions of storage for 150 days. $A=$ chamber, $B=$ room temperature and humidity conditions and $C=$ refrigerator.

Quanto às sementes acondicionadas em saco de papel na geladeira, houve redução no teor de água, a partir do início do armazenamento, quando elas atingiram $7 \%$ de umidade no final do período de armazenamento. As acondicionadas em saco de polietileno sofreram pequena redução de umidade logo no início do armazenamento, mantendo-se até os 60 dias, quando houve redução, alcançando no final 7,2\% de umidade.

R. Árvore, Viçosa-MG, v.29, n.6, p.833-841, 2005 
Nesse ambiente de armazenamento, em ambas as embalagens houve tendência de queda no teor de água ao longo do tempo, devido à menor umidade relativa do ar. No entanto, os valores de umidade das sementes acondicionadas na embalagem de papel foram inferiores aos 30, 60, 120 e 150 dias de armazenamento, com destaque, sobretudo, para os dois primeiros períodos. Tais observações são reforçadas por Greg et al. (1970), que mencionaram que o seu conteúdo de água das sementes, devido à sua propriedade higroscópica, variam com a umidade relativa do ar.

Nas sementes ortodoxas, o teor de água é um dos fatores mais importantes para a manutenção da sua viabilidade ao longo do tempo. A redução no teor de água das sementes causa diminuição da sua atividade metabólica, o que prolonga a viabilidade delas (FOWLER, 2000).

De acordo com as curvas ajustadas para o índice de velocidade de germinação (Figura 2A), os dados revelaram, na análise de regressão, efeito quadrático nas sementes acondicionadas nas duas embalagens (papel e polietileno) no ambiente de câmara. Pode-se constatar, nessa condição de armazenamento, que as sementes tiveram comportamento semelhante entre si, com valores de vigor condicionados pelos períodos de armazenamento, sobressaindo a embalagem de polietileno, em que as sementes se mostraram mais vigorosas, alcançando o máximo logo no início do armazenamento.

Em condições de laboratório (Figura 2B), constatouse efeito linear em ambas as embalagens. Nesse ambiente, também se observou comportamento semelhante das sementes acondicionadas nas duas embalagens, com perda total de vigor aos 120 dias de armazenamento. Resultados semelhantes foram obtidos por Perez et al. (1999); sementes de canafístula acondicionadas em embalagem de vidro, mantidas em temperatura de ambiente de laboratório, reduziram o vigor (IVG) após 90 dias de armazenamento.

Nas sementes mantidas em ambiente de geladeira, acondicionadas em sacos de papel e de polietileno (Figura 2C), os dados se ajustaram a modelo linear de efeitos quadrático e linear, respectivamente. Durante o armazenamento, constatou-se nas sementes acondicionadas em saco de papel uma queda máxima no vigor $(0,09)$ aos 111 dias de armazenamento, apresentando, no final, a menor velocidade de germinação.
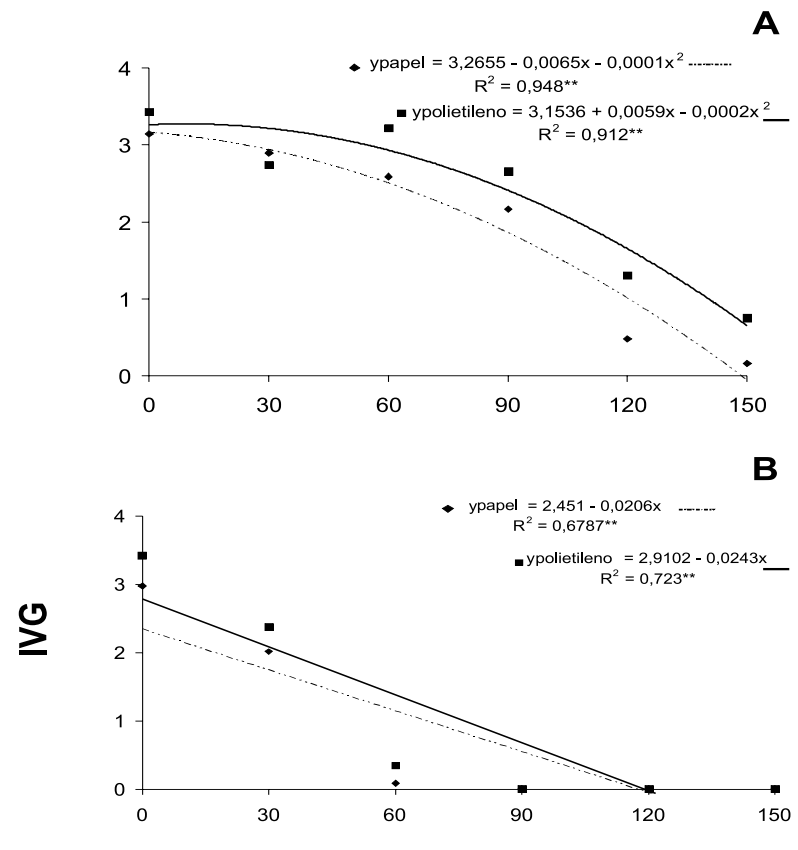

C

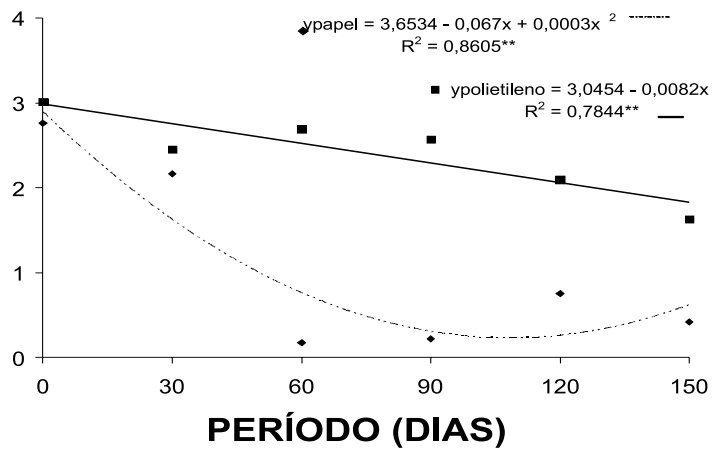

Figura 2 - Índice de velocidade de germinação de sementes de ipê-amarelo acondicionadas em diferentes embalagens e armazenadas sob diferentes condições por 150 dias. $\mathrm{A}=$ câmara, $\mathrm{B}=$ laboratório e $\mathrm{C}=$ geladeira.

Figure 2-Germination speed index of yellow-ipe seeds stored in different packaging and conditions of storage for 150 days. $A=$ chamber, $B=$ room temperature and humidity conditions and $C=$ refrigerator.

Com as sementes acondicionadas em saco de polietileno houve pequena redução no vigor ao longo do armazenamento. No decorrer desse tempo, as sementes mantidas no refrigerador e acondicionadas na embalagem de polietileno apresentaram-se mais vigorosas, em relação àquelas acondicionadas na mesma embalagem e armazenadas tanto na câmara quanto no laboratório. 
Sementes de ipê-rosa acondicionadas na embalagem impermeável (saco plástico) e armazenadas no ambiente de câmara fria $\left(5^{\circ} \mathrm{C} \mathrm{e} 90 \%\right.$ UR) por 489 dias apresentaram o maior índice de velocidade de germinação, em comparação com os ambientes não-controlados de laboratório e de câmara seca (SILVA et al., 2001).

Quanto ao comprimento da parte aérea, as sementes acondicionadas nas duas embalagens e armazenadas na câmara (Figura 3A) apresentaram redução no vigor ao longo do tempo de armazenamento, com pequenas oscilações entre as duas embalagens estudadas.

No ambiente de laboratório, em ambas as embalagens os dados médios de comprimento de parte aérea de plântulas se ajustaram a equações de efeito quadrático (Figura 3B), havendo pequena diferença entre as sementes acondicionadas nas duas embalagens, perdendo rapidamente o vigor aos 120 dias.

Considerando o ambiente de geladeira, observouse efeito linear somente nos valores médios de comprimento de parte aérea de plântulas resultantes de sementes acondicionadas em saco de polietileno (Figura 3C), o qual se mostrou superior à embalagem de papel, a partir dos 30 dias de armazenamento. Os tratamentos que apresentam maiores valores de comprimento médio de plântulas normais ou das partes destas foram considerados por Vieira e Carvalho (1994) como mais vigorosos. Desse modo, as sementes vigorosas originam plântulas com maior taxa de crescimento, em razão de apresentarem maior capacidade de translocação de suas reservas e maior assimilação destas pelo eixo embrionário. Em geral, os cotilédones têm como função manter a plântula no princípio de sua vida, fornecendolhe os nutrientes armazenados ou fotossintetizados. No presente trabalho, como as plantas contavam com 21 dias após a germinação, a translocação de nutrientes e, conseqüentemente, a atividade fotossintética foram realizadas pelas folhas propriamente ditas (metáfilos) ou, ainda, transitoriamente, pelos protófilos (OLIVEIRA, 1993).

Considerando os ambientes de câmara e geladeira, constatou-se a superioridade das sementes acondicionadas na embalagem de polietileno, as quais se mostraram mais vigorosas ao longo do armazenamento. Resultados obtidos por Garcia e Lima (2000), no teste de vigor baseado no comprimento da parte aérea de plântulas de copaíba, não se mostraram eficientes em detectar diferenças entre as embalagens utilizadas (saco de papel e vidro) no ambiente de laboratório. Entretanto, no ambiente de câmara fria o comprimento de plântulas mostrou-se sensível, ao ponto de detectar diferenças significativas entre as embalagens.

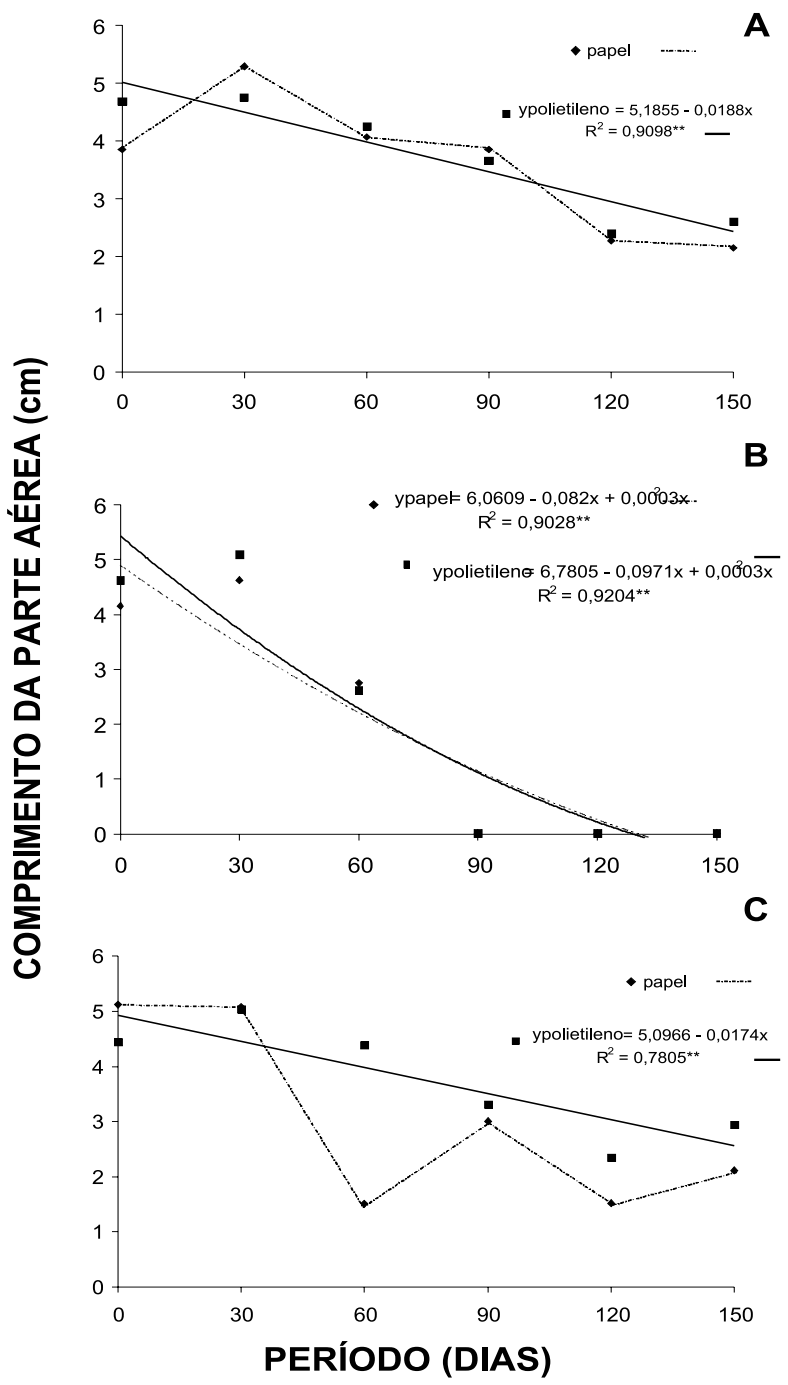

Figura 3 - Comprimento da parte aérea de plântulas de ipêamarelo acondicionadas em diferentes embalagens e armazenadas sob diferentes condições por 150 dias. $\mathrm{A}=$ câmara, $\mathrm{B}=$ laboratório e $\mathrm{C}=$ geladeira.

Figure 3-Length of the aerial part of yellow-ipe seedlings stored in different packaging and conditions of storage for 150 days. $A=$ chamber, $B=$ room temperature and humidity conditions and $C=$ refrigerator.

Baseado na análise dos dados de comprimento de raiz de plântulas de ipê-amarelo, armazenadas na câmara, detectou-se um efeito quadrático nas sementes mantidas na embalagem de papel, bem como um linear naquelas em saco de polietileno (Figura 4A).

R. Árvore, Viçosa-MG, v.29, n.6, p.833-841, 2005 


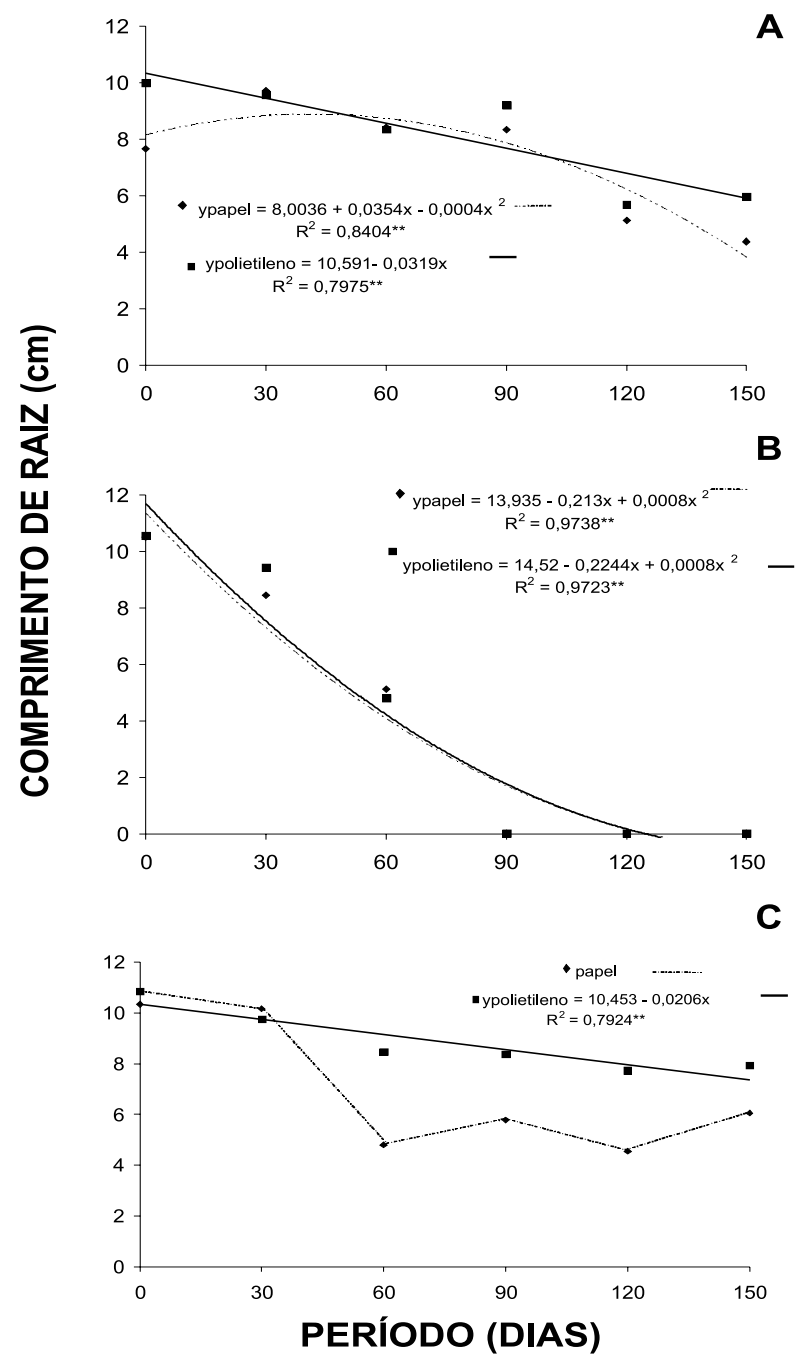

Figura 4 - Comprimento de raiz de plântulas de ipê-amarelo acondicionadas em diferentes embalagens e armazenadas sob diferentes condições por 150 dias. $\mathrm{A}=$ câmara, $\mathrm{B}=$ laboratório e $\mathrm{C}=$ geladeira.

Figure 4-Root length of yellow-ipe seedlings stored in different packaging and conditions of storage for 150 days. $A=$ chamber, $B=$ room temperature and humidity conditions and $C=$ refrigerator.

Comparando as duas embalagens, observou-se que as sementes acondicionadas em papel produziram plântulas com menor comprimento de raiz, no início e no final do armazenamento. De modo geral, sementes acondicionadas em saco de polietileno e armazenadas na câmara originaram plântulas mais vigorosas do que aquelas acondicionadas em sacos de papel por 30 dias e a partir de 90 dias de armazenamento.
Em se tratando do ambiente de laboratório, os valores médios de comprimento de raiz procedentes de sementes acondicionadas nas duas embalagens se ajustaram a equações de efeito quadrático (Figura 4B). Detectou-se drástica redução nos valores de comprimento de raiz nas duas embalagens nesse ambiente, podendo constatar que o ambiente exerceu maior influência que a embalagem sobre o vigor de plântulas. Maeda e Matthes (1984), pesquisando diferentes espécies de Tabebuia em embalagem de papel à temperatura ambiente, observaram que sementes de Tabebuia impetiginosa reduziram a viabilidade em $72 \%$, aos 40 dias de conservação.

No ambiente de geladeira, nas sementes acondicionadas na embalagem de polietileno houve efeito linear para os valores médios de comprimento de raiz (Figura 4C). Nessa embalagem, as sementes apresentaram pequena redução do vigor ao longo do armazenamento. Já, nas sementes acondicionadas em saco de papel, estas produziram plântulas menos vigorosas, a partir dos 30 dias de armazenamento.

Pesquisando níveis de vigor entre lotes de sementes de aveia-preta, Schuch et al. (1999) constataram que o comprimento das raízes é o parâmetro mais adequado, para avaliações de diferenças no vigor de sementes dessa espécie, do que o comprimento da parte aérea, tendo propiciado diferenciação entre níveis de vigor em todas as épocas de avaliação.

Os dados de massa seca de parte aérea de plântulas provenientes de sementes de ipê-amarelo acondicionadas nas embalagens de papel e polietileno e armazenadas na câmara ajustaram-se ao modelo de regressão linear de efeitos quadrático e linear, respectivamente (Figura 5A). Na embalagem de papel, as plântulas apresentaram-se menos vigorosas no início do armazenamento do que aquelas oriundas de sementes acondicionadas na embalagem de polietileno, exibindo o máximo de massa seca $(0,01 \mathrm{~g})$ aos 60 dias. Já na embalagem de polietileno houve redução linear no peso de massa seca de 0,0005 g a cada período de armazenamento.

Com relação ao ambiente de laboratório, os valores de massa seca de parte aérea ajustaram-se a equações de efeito linear, nas duas embalagens (Figura 5B). Observase, nessa figura, comportamento semelhante, ao longo do armazenamento, quanto às embalagens utilizadas, com menor perda de peso de massa seca naquelas sementes mantidas em embalagem de polietileno. 


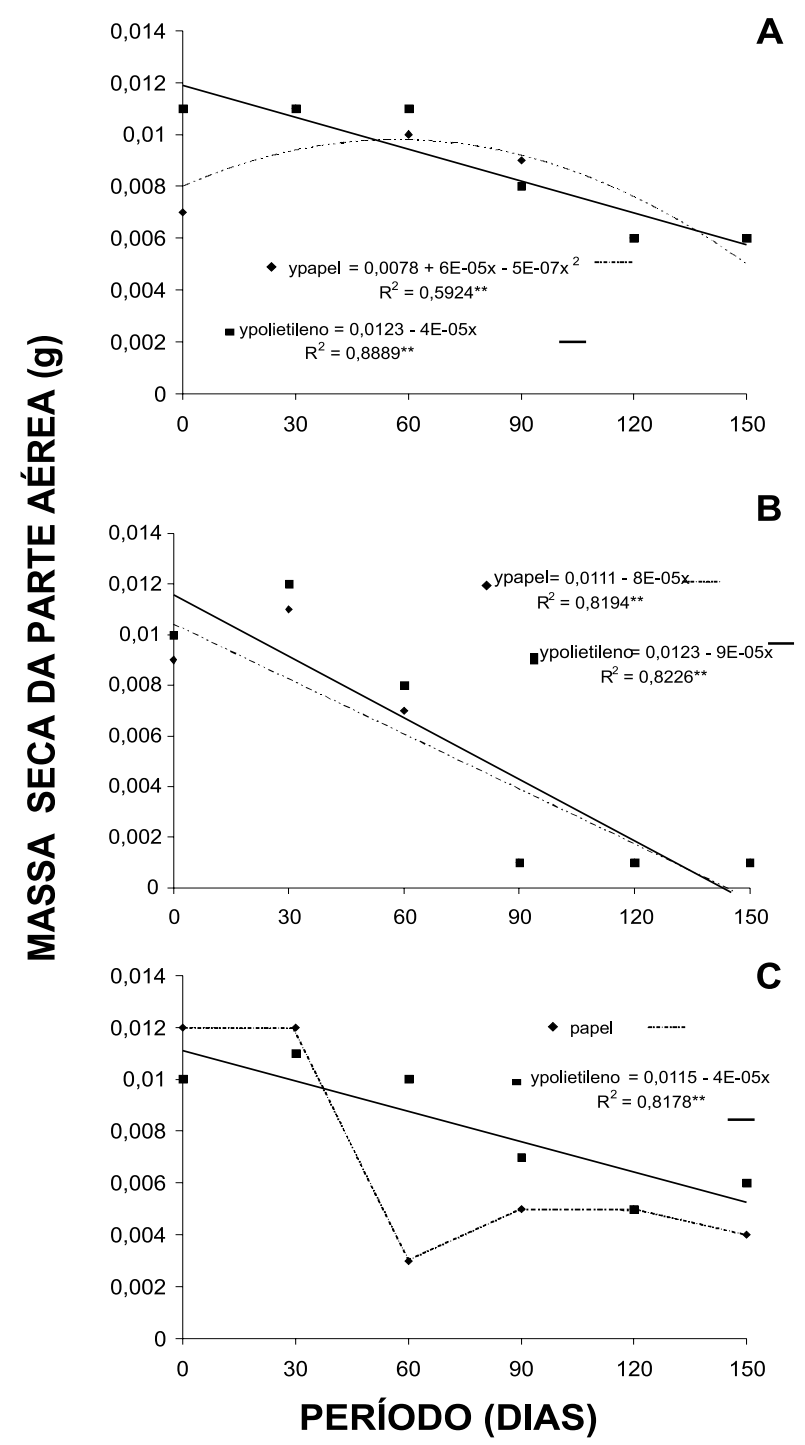

Figura 5 - Massa seca da parte aérea de plântulas de ipêamarelo acondicionadas em diferentes embalagens e armazenadas sob diferentes condições por 150 dias. $\mathrm{A}=$ câmara, $\mathrm{B}=$ laboratório e $\mathrm{C}=$ geladeira.

Figure 5-Dry matter of the aerial part of yellow-ipe seedlings stored in different packaging and conditions of storage for 150 days. $A=$ chamber, $B=$ room temperature and humidity conditions and $C=$ refrigerator.

Quanto ao ambiente geladeira, apenas na embalagem de polietileno houve efeito linear (Figura 5C). Constatouse redução no peso de massa seca da parte aérea de plântulas, nessa embalagem, de $0,0005 \mathrm{~g}$ a cada período de armazenamento, ocorrendo menor queda em peso de madeira seca que a embalagem de papel, a partir dos 30 dias até o final do armazenamento. Já na massa seca de plântulas produzidas nessa última embalagem se observou menor vigor das plântulas ao longo do armazenamento.

Segundo Nakagawa (1994), durante a germinação as sementes vigorosas proporcionam maior transferência de massa seca de seus tecidos de reserva para o eixo embrionário, originando plântulas com maior peso, em razão do maior acúmulo de matéria.

Aos dados de massa seca de raiz de plântulas originadas de sementes de ipê-amarelo acondicionadas nas embalagens de papel e polietileno armazenadas na câmara, ajustaram-se equações de regressão de efeitos quadrático e linear, respectivamente (Figura 6A). Observa-se, nessa figura, na utilização da embalagem de papel, que houve ganho em peso de massa seca de raiz de plântulas, a partir dos 30 dias de armazenamento, mostrando-se superior à embalagem de polietileno no período de 30 dias, atingindo valor máximo $(0,012 \mathrm{~cm})$ aos 45 dias. Na embalagem de polietileno, constatou-se decréscimo linear de $5 \times 10^{-7} \mathrm{~g}$ no peso de massa seca de raiz de plântulas, a cada período de armazenamento.

Quanto ao ambiente laboratório, houve efeito quadrático nos valores de massa seca de raiz de plântulas nas embalagens utilizadas (Figura 6B). Pode-se constatar, nessa figura, comportamento muito semelhante entre as embalagens, com rápida redução no peso de massa seca de raiz, com valores mínimos tendendo a zero ao final do período de armazenamento.

Verifica-se, na Figura 6C, efeito linear apenas nos dados de peso de massa seca de raiz de plântulas, com redução de $5 \times 10^{-3} \mathrm{~g}$ de massa seca, a cada período de armazenamento, durante a utilização da embalagem de polietileno para estocagem das sementes de ipêamarelo em geladeira. Na embalagem de papel, constataram-se variações ao longo do armazenamento, ocorrendo, a partir dos 30 dias, queda brusca no vigor. Constatou-se, mais uma vez, destaque das sementes acondicionadas na embalagem polietileno ao longo do armazenamento. Em média, os valores máximos obtidos com o peso de massa seca de plântulas, durante o armazenamento em geladeira, resultam do efeito da embalagem de polietileno, em que as sementes apresentaram pequena redução no vigor.

R. Árvore, Viçosa-MG, v.29, n.6, p.833-841, 2005 

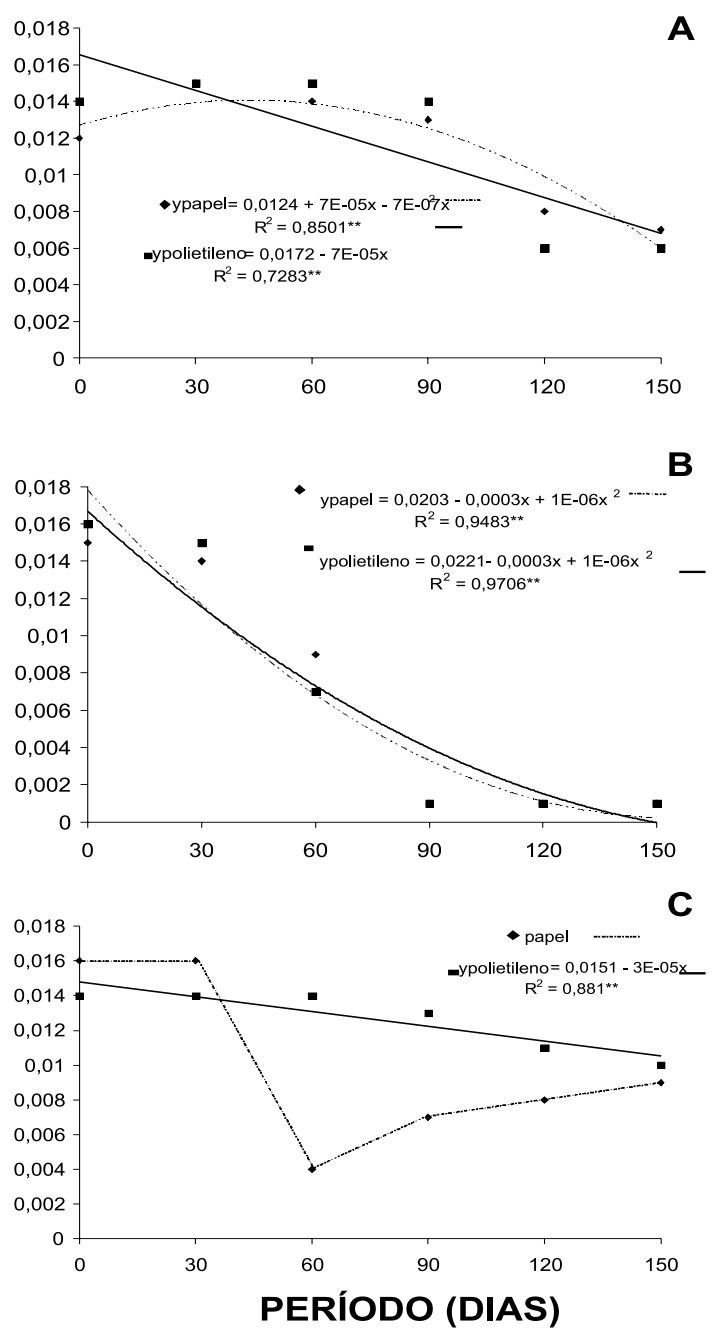

Figura 6 - Massa seca de raiz de plântulas de ipê-amarelo acondicionadas em diferentes embalagens e armazenadas sob diferentes condições por 150 dias. $\mathrm{A}=$ câmara, $\mathrm{B}=$ laboratório e $\mathrm{C}=$ geladeira.

Figure 6-Dry matter of root of yellow-ipe seedlings stored in different packaging and conditions of storage for 150 days. $A=$ chamber, $B=$ room temperature and humidity conditions and $C=$ refrigerator.

\section{CONCLUSÕES}

Nas condições do presente trabalho, concluiuse que:

As sementes de ipê-amarelo acondicionadas na embalagem de papel apresentaram maior teor de água ao longo do período de armazenamento, nos ambientes de câmara e condições normais de laboratório.
Em geral, as sementes acondicionadas nas embalagens de papel e polietileno e armazenadas no ambiente de laboratório apresentaram maior perda de vigor ao longo do armazenamento.

\section{REFERÊNCIAS BIBLIOGRÁFICAS}

BONNER, F.T. Storage of seeds: Potential and limitations for germoplasm conservation. Forest Ecology and Management, v.35, p.35-43, 1990.

BRASIL. Ministério da Agricultura e Reforma Agrária. Regras para análise de sementes. Brasília: SNDA/DNDV/CLAV, 1992.365p.

CARVAlHO, N.M.; NAKAGAWA, J. Sementes: ciência, tecnologia e produção. 4.ed. Jaboticabal: FUNEP, 2000. 588p.

DEGAN, P. et al. Influência de métodos de secagem na conservação de sementes de ipêbranco. Revista Brasileira de Engenharia Agrícola e Ambiental, v. 5, n. 3, p. 492-496, 2001.

FIGLiOliA, M.B. Conservação de sementes de essências florestais. São Paulo: Instituto Florestal, 1988. 18p. (Boletim Técnico, 42)

FOWLER, J.A.P. Superação de dormência e armazenamento de sementes de espécies florestais. In: GALVÃO, A.P.M. (Org.) Reflorestamento de propriedades rurais para fins produtivos e ambientais: um guia para ações municipais e regionais. Brasília:Embrapa Comunicação para Transferência de Tecnologia; Colombo, PR: Embrapa Florestas, 2000. p. 77-99.

GARCIA, L.C.; LIMA, D. Comportamento de sementes de Copaifera multijuga Hayne durante o armazenamento. Acta Amazônica, v. 30, n.3, p. $369-375,2000$.

GREG, B.R. et al. Seed processing. Nova Delhi: Avion Printers, 1970. 396p.

LEÃO, N.V.M. Conservação de sementes de morototó (Didymopanax morototonii (Aublet) Decne.). Belém: Embrapa-CPATU, 1984. 16p. (Embrapa-CPATU. Boletim de Pesquisa, 64). 
MAEDA, J.A.; MATTHES, L.A.F. Conservação de sementes de ipê. Bragantia, v.43, n.1, p.51-61, 1984 .

MAGUIRE, J.D. Speed of germination in selection and evaluation for seedling emergence and vigor. Crop Science, v.2, n.2, p.176-177,1962.

NAKAGAWA, J. Testes de vigor baseados na avaliação das plântulas. In:VIEIRA, R.D.; CARVALHO, N.M. Teste de vigor em sementes. Jaboticabal, FUNEP, 1994. p.49-85.

OLIVEIRA, E.C. Morfologia de plântulas.In: AGUIAR, I.B.; PIÑA-RODRIGUES, F.C.M.; FIGLIOLIA, M.B. Sementes florestais tropicais. Brasília: ABRATES, 1993, p.175-213.

PEREZ, S.C.J.G.A.; FANTI, S.C.; CASALI, C.A. Influência do armazenamento, substrato, envellhecimento precoce e profundidade de semeadura na germinação de canafístula. Bragantia, v. 58, n. 1, p. 57-68, 1999.

ROBERTS, E.H. Predicting the storage life of seeds. Seed Science and Technology, v. 1, n. 3, p. 499-514, 1973.
SAEG. Sistema para análises estatísticas; versão 5.0. Viçosa, MG: Fundação Arthur Bernardes, 1993.

SCHUCH, L.O.B. et al. Crescimento em laboratório de plântulas de aveia-preta (Avena strigosa Schreb.) em função do vigor das sementes.

Revista Brasileira de Sementes, v.21, n.1, p.229-234, 1999.

SILVA, A. et al. Liofilização e armazenamento de sementes de ipê-rosa (Tabebuia heterophylla (A.P. Candolle)Britton) - Bignoniaceae.

Revista Brasileira de Sementes, v. 23, n. 1, p.252-259, 2001.

SOUZA, S.M.; PIRES, I.E.; LIMA, P.C.F. Influência da embalagem e condições de armazenamento na longevidade de sementes florestais. In: EMPRESA BRASILEIRA DE PESQUISAAGROPECUÁRIA.

Pesquisa Florestal do Nordeste semiárido: sementes e mudas. Petrolina: Embrapa/CPATSA, 1980, p.15-24 (Boletim de Pesquisa, 2).

VIEIRA, R.D.; CARVALHO, N.M. Teste de vigor em sementes. Jaboticabal: FUNEP, 1994. 164p. 